\section{Remember the days in the old school yard: from lectures to online learning}

\author{
P. A. Reynolds, ${ }^{1}$ R. Mason ${ }^{2}$ and K. A. Eaton ${ }^{3}$
}

VERIFIABLE CPD PAPER
IN BRIEF

- Gives an overview of the impact of e-learning on teaching practice and introduces themes which will be developed in the next five papers in the current series.

- Suggests that the impact of ICT systems and services has and will continue to transform teaching practice at all levels of education.

- Suggests that in some ways tertiary education, has been slow to grasp the opportunities that e-learning offers.

Claims have been made that the traditional classroom/lecture-room mode of teaching is under threat with the future being purely online-based. There is no doubt that the impact of ICT systems and services have and will continue to transform teaching practice. From PowerPoint slides introduced to enliven lectures to virtual reality models accessed remotely, technology is bringing about new educational paradigms. The result is the emergence of new forms of distance learning with terms such as flexible learning, blended learning and full online instruction. All are making major contributions to the student experience, allowing access to more information and greater resources as well as opportunities for learning in a manner and timescale that is more attuned to their aims, abilities and lifestyles. In dental education the transition is providing undergraduates, postgraduates and CPD students with a greater variety of courses, access to more expertise and the opportunity for lifetime learning.

\section{E-LEARNING IN DENTISTRY}

Section A: Teaching and technology

1. A description of the new technologies used in transforming dental education

2. Seeing is believing: dental education benefits from developments in videoconferencing

3. Webcasting: casting the web more widely

4. Top of the pops - CD-ROM and DVDs in dental education

Section B: Informatics: better informed by systems and services

5. Better informed: an overview of health informatics

6. Better informed in clinical practice a brief overview of dental informatics

7. Digital clinical records and practice administration in primary dental care

Section C: Impact of e-learning in

dental education

8. Remember the days in the old school yard: from lectures to online learning

9. An intricate web - designing and authoring a web-based course

10. The many faces of interaction

11. Supporting the learner and teacher online

12. Making a mark - taking assessment to technology

13. Continuing professional development and ICT: target practice

14. Assuring quality

Section D: A connected future

15. Nine years of DentEd: a global perspective

16. A vision of dental education in the third millenium

\section{Introduction}

In recalling schooldays (and the pop songs), memories are of blackboard and chalk, together with a 'talking head' teacher standing in front of the class with material that had hardly changed, apparently, from Victorian times. It was a didactic method, learning by rote, and not very exciting, stimulating, enlightening or challenging. Nor was it designed for the student to assimilate whatever pearls of wisdom were emanating from the pedagogue. It hardly involved the student in the learning process, as it tended to be dry, unimaginative and text-book-based. It is a scenario that brings to mind the famous remark - 'Lectures are the process of transferring information from teacher's notes to

\footnotetext{
${ }^{1 *}$ Professor of Dental Education, Centre of Flexible Learning in Dentistry, King's College London Dental Institute, Floor 3, Strand Bridge House, 138-142

Strand, London, WC2 $1 \mathrm{HH} ;{ }^{2}$ Professor of Educational Technology, Institute of Educational Technology, The Open University, Walton Hall, Milton Keynes, MK7 6AA ${ }^{3}$ Visiting Professor, UCL Eastman Dental Institute, 256 Gray's Inn Road, London, WC1X 8LD

${ }^{*}$ Correspondence to: Professor P. A. Reynolds Email:P.A.Reynolds@kcl.ac.uk
}

\section{Refereed Paper}

DOI: 10.1038/sj.bdj.2008.299

${ }^{\circ}$ British Dental Journal 2008; 204: 447-451 students' notes without going through the minds of either.'

Sadly too much teaching is still conducted on these lines, though this is now mainly at a Higher Education (HE) level, as schools have generally been ahead of tertiary education establishments in adopting e-learning. The most important catalyst for this has been the emergence of an evidence base supporting e-learning and the use of information communications technology (ICT).

This development in HE can initially be seen as transforming delivery from lectures to online. The current series of articles has revealed that the systems and services are in place to effect this transformation; now the question should be asked: 'How does it impact on those in education whether as students or teachers?'

There is, of course, the risk that educationalists will see this as a panacea and a word of warning is appropriate. Technology does not turn a poor teacher into a good one. Style, commitment, love and knowledge of the subject, content and creativity, and concern for the students will always remain prerequisites. However, a good teacher will be a good teacher in any medium, ${ }^{1}$ with an innate 
understanding of the needs of their students whatever the technology.

Technology should be seen as the enabler, with its various emanations - the Internet, CD-ROM, videoconferencing, webcasting, computers and, most recently, virtual reality - the enabling tools. At the simplest level such technologies can enhance the traditional lecture-based approach. The inclusion of PowerPoint slides may well add life to an otherwise dull, verbal address especially if the full range of the program's features are utilised.

Within PowerPoint ${ }^{2}$ there are opportunities to add visuals including photographs, graphs and charts, linedrawings, and special text effects. The danger, of course, is that not everybody has graphic design skills and the resulting presentations can end up resembling a poor attempt at modern art rather than a teaching aid!

\section{The first steps}

PowerPoint is probably the most obvious example of the upgrading of the traditional lecture, but there are other methods. Previous articles in this series have covered videoconferencing ${ }^{3}$ and webcasting, ${ }^{4}$ both of which can be used to interleave external resources, such as an expert, or for involving students in another lecture. In addition they have permitted cross- and inter-campus links to promulgate the lectures and material to a wider student body, thereby saving teaching resources while providing a consistently high level of education. Planning a lecture becomes more crucial not just in terms of content, where thinking in pictures will be as important as thinking in words, but also in meshing all the various elements and feeds together into a coherent presentation.

In this scenario technology is being used as an addition to the existing classroom or lecture theatre setting. As has been said, 'Nowadays it appears fundamental to adopt a more integrated version where ICT is considered together with education strategies, content and activities the students engage in. ${ }^{5}$

The full impact of the technology and its concomitant services is realised when they are applied to distance learning.
Distance learning is not new. It can be traced it back to Gutenberg's invention of printing (from which emerged the 'independent learner'), through the radio and television to the Internet. ${ }^{6}$ From individual reading in the library, distance learning has progressed through correspondence courses to today's distributed classroom.

Distance learning was already being offered by London University 150 years ago and more recently, by the Open University (OU), which opened in 1969 and has blazed the trail for flexible methods of teaching and learning. The original OU courses were primarily based on printed material which was mailed to students. They soon became enhanced through the use of TV and radio and were (and are) often broadcast at night.

These media were essentially asynchronous (one-way), ie information and ideas were downloaded to the student without any opportunity for two-way dialogue and interaction. This sense of isolation amongst students was further exacerbated by the lack of many opportunities for collaboration with their peers or with tutors, despite the organisation of a number of tutorials and summer schools. The loneliness of the long distance learner was well known. Further, students, with few exceptions, could not enjoy the facilities common to traditional universities. Libraries and laboratories in particular were resources that, especially for research purposes, were difficult to access.

\section{Defining distance learning}

The definition of distance learning is sometimes confused with terms such as e-learning, online learning and flexible learning. It can be argued that these more recent terms are subsets of distance learning, or that all are subsets of flexible learning. It has been argued, for example, that 'Online education is a subcategory of distance learning which has been defined as the formal delivery of instruction in which time and geographic location separate students and instructor', ${ }^{7}$ while e-learning has been described as 'learning in a way that uses information and communication technologies.'

The search and research functionality of the Internet is a valuable resource that overcomes one of the major limitations of traditional distance learning. In addition, collaboration and contact, whether with teaching staff or fellow students, can be more frequent and easier through utilities such as chat rooms, email, and bulletin boards and videoconferencing - in fact, what is being described is e-learning.

In this new paradigm 'distance learning' represents a change in the fundamental orientation of the learning environment. Traditional, physically co-present classrooms and pedagogical practices involve face-to-face instructorlearner relationships. These physically and socially immediate instructional contexts are transformed in distance learning through, typically, the technological intermediation of communication between teacher and student. One observer believes that 'Basically it is distance learning being modernised... instead of letters and television being the instructional mediums, computers, modems and the internet are the means by which teachers and students connect. ${ }^{9}$

\section{e-Learning benefits}

Through e-learning students can work at their own pace and learn 'flexibly' - anytime and anywhere. Course material and information can be accessed or downloaded via the Internet and a range of assessment techniques can be used. For teaching staff there is the benefit of being able to update courses quickly and of being removed from repetitive teaching tasks.

In what may seem a compromise, blended learning has emerged, a combination of 'face-to-face and online teaching. The two are complementary and synergistic and also allow greater flexibility in learning. This approach can also be used by the dental team to maintain lifelong learning. ${ }^{10}$ A major advantage of blended learning is that it puts the student at the centre of education rather than the teacher. According to the UK Government's e-learning strategy consultative document, e-learning can help to deliver the means to empower learners, for example by enabling more active learning. ${ }^{11}$ It also foresees an 
Table 1 Ideal importance of media components in Open University Courses - by subject area

\begin{tabular}{l|l|l|l} 
& Humanities & Science & Technology \\
\hline Course programmes on TV & 83.7 & 68.9 & 52.9 \\
\hline Computer disks, CD-ROMs etc sent to you & 78.9 & 86.1 & 95.1 \\
\hline Online materials and resources you can access & 69.2 & 75.7 & 81.3 \\
\hline Online courses, email, conferencing & 58.4 & 71.9 & 81.3 \\
\hline (Base: percentage of respondents in each subject rating the component as either 'Very important' or 'Quite important
\end{tabular}

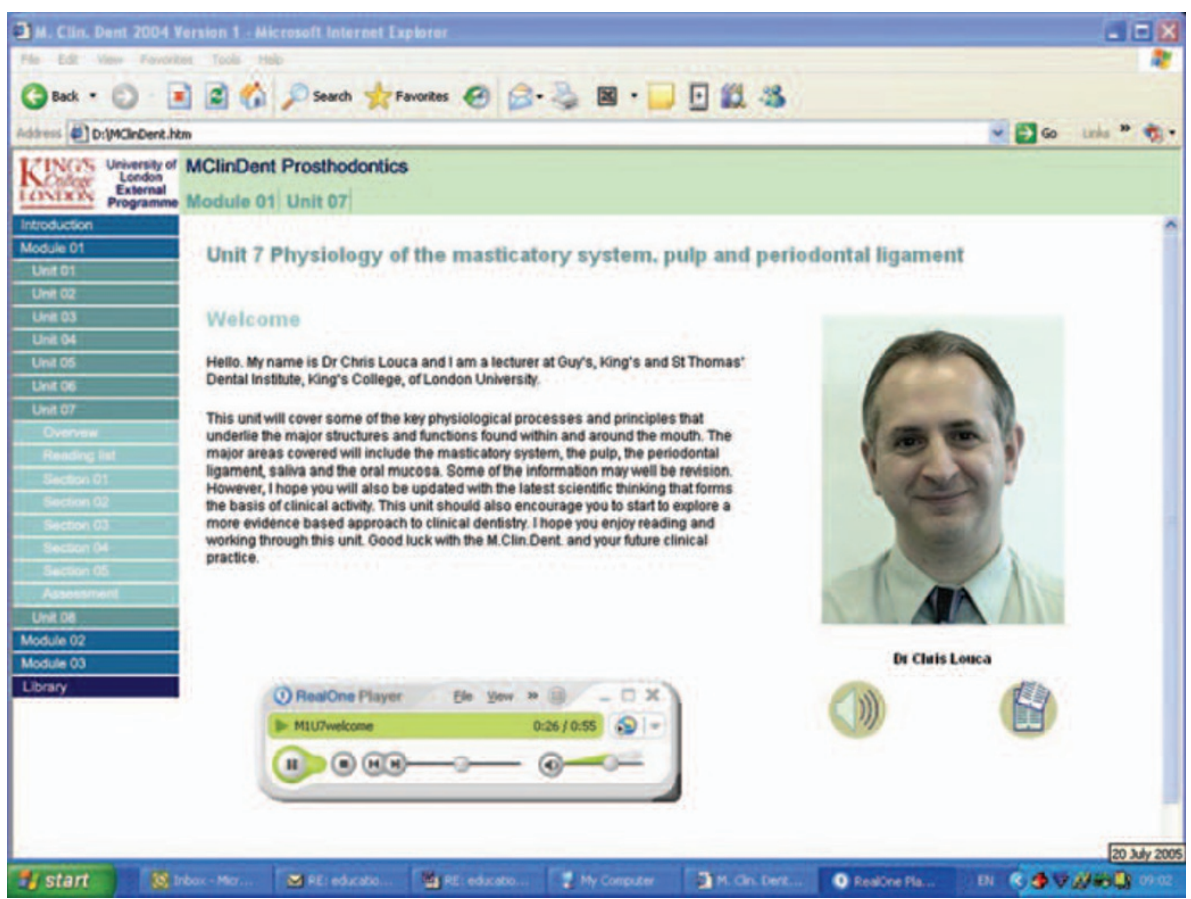

Fig. 1 Screen shot of MClinDent webpage

education system that is more flexible and responsive to individual needs. ${ }^{11}$

The raft of new technologies that have appeared over the past 20 years and their amalgamation into e-learning have led some, at least, to question the continuing viability of classroom-based learning and its total replacement by online courses. There are many propagandists for this development. 'Today very little is needed in order to disseminate online training to a mass audience. With the web, at the simplest level, all that is needed is a server or a web host and access built with a language, like HTML or using a PowerPoint converter. Instantly you have "content" online and accessible by a pervasive audience. ${ }^{12}$ However, e-learning can offer far more profound opportunities in personalised and student-centred learning - the term 'technologically enhanced learning' has now been coined. ${ }^{13}$
Postgraduate students are often also in full-time work and find it difficult to travel to a central teaching location. For some, especially those based overseas, there is a lack of such courses in their own countries. In these cases the only solution is provided by distance learning, perhaps delivered as e-learning. However, it should not solely consist of downloading course material onto a distant computer, it is more than that. 'Possibilities for teaching with the Internet include using it as a source of information, a means of representing content, a means of communication, or a site for collaboration.' ${ }^{14}$

Learning online demands flexibility, with students taking more responsibility for the pace and structure of their studies, ie they can learn in their own time, their own workplace and continue the process to suit their own needs. It is

\section{A practical approach}

not the top-down, rigid structure of the classroom. As has been stated, 'With the current trend in pedagogy away from didactic, instrumental learning towards more constructivist and resource-based approaches, students are being encouraged to go beyond the supplied course material and research materials for themselves, often discussing their findings in computer conferences. ${ }^{14}$

Just as teaching staff have to be au fait and confident with ICT, so must students be. Research undertaken by the Open University ${ }^{15}$ showed that amongst their students, TV programmes were more likely to be watched by humanities students than those on science and technology courses; the reverse was true for computer disks and CD-ROMs. Other ICT functions showed a similar pattern (Table 1).

It may not be surprising that Arts students are less likely to be technophiles than their science and technology counterparts, but there must be concern that 'students who are technologically illiterate tend to spend many hours trying to figure out how to use online technologies, communicate with instructors, submit online assignments, or download classrelated material from the class website. ${ }^{16}$ Nor must it be forgotten that those in the developing world, in particular, may not be able to benefit from e-learning which, for them, may remain an aspiration rather than a reality. One of the major responsibilities of the education world must, therefore, be to ensure that ICT infrastructure and systems are made available and accessible worldwide.

\section{Innovative approaches}

Through the partnership of educationalists and computer scientists, innovative educational tools and interactive new formats have evolved and virtual learning environments (VLEs) have been created as "the guide on the side rather than sage on the stage. ${ }^{17}$ This is best exemplified by the Masters in Clinical Dentistry, Fixed and Removable Prosthodontics ${ }^{18}$ course, which is now offered as an online course with annual residential components. Students are able to access course materials and submit assignments online and interact with tutors and other students through a VLE (Fig. 1). 


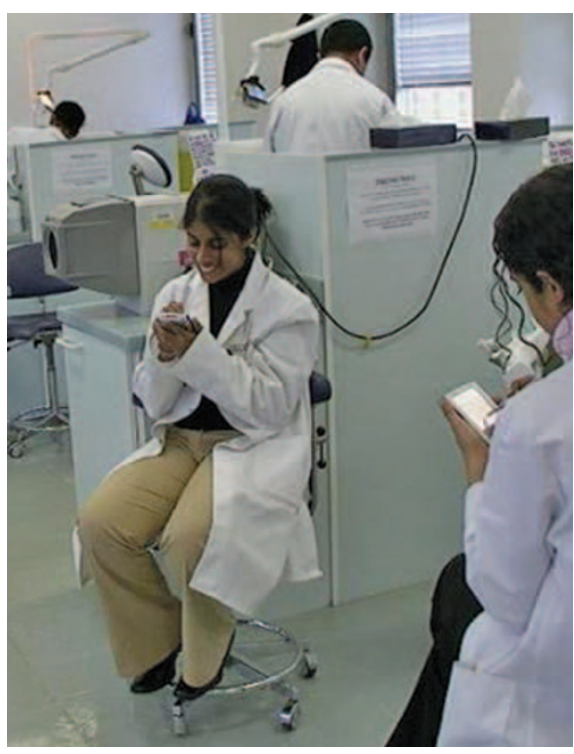

Fig. 2 Using a PDA in the clinic

The two-week extensive residential study period for this course, involving lectures, clinical demonstrations, laboratory work, seminars and tutorials, is the only face-to-face teaching and learning component that students experience. Similarly, some of the Institute's undergraduate courses take this blended approach, with the online component enhancing practical classes.

\section{On the move}

The dramatic growth of mobile technologies, whether for voice, data or images, is one of the most noticeable features of ICT in the past few years. Given that students are more than familiar with the use of mobile phones and other wireless devices, it would appear that mobility can add another dimension to education and training.

Apart from the normal Global System for Mobile Communications (GSM) phone, which provides limited data facilities, there are the alternatives of general packet radio service (GPRS), which expands the data possibilities through its faster transmission speed, and the potential of using laptops either through a connection via a mobile phone, or via the latest wireless local area network (WiLAN) services or worldwide interoperability for microwave access (Wi-MAX). In addition the emerging availability of third generation (3G) services will possibly make the mobile phone a far more versatile mode of access to education. Whichever is used, students, especially

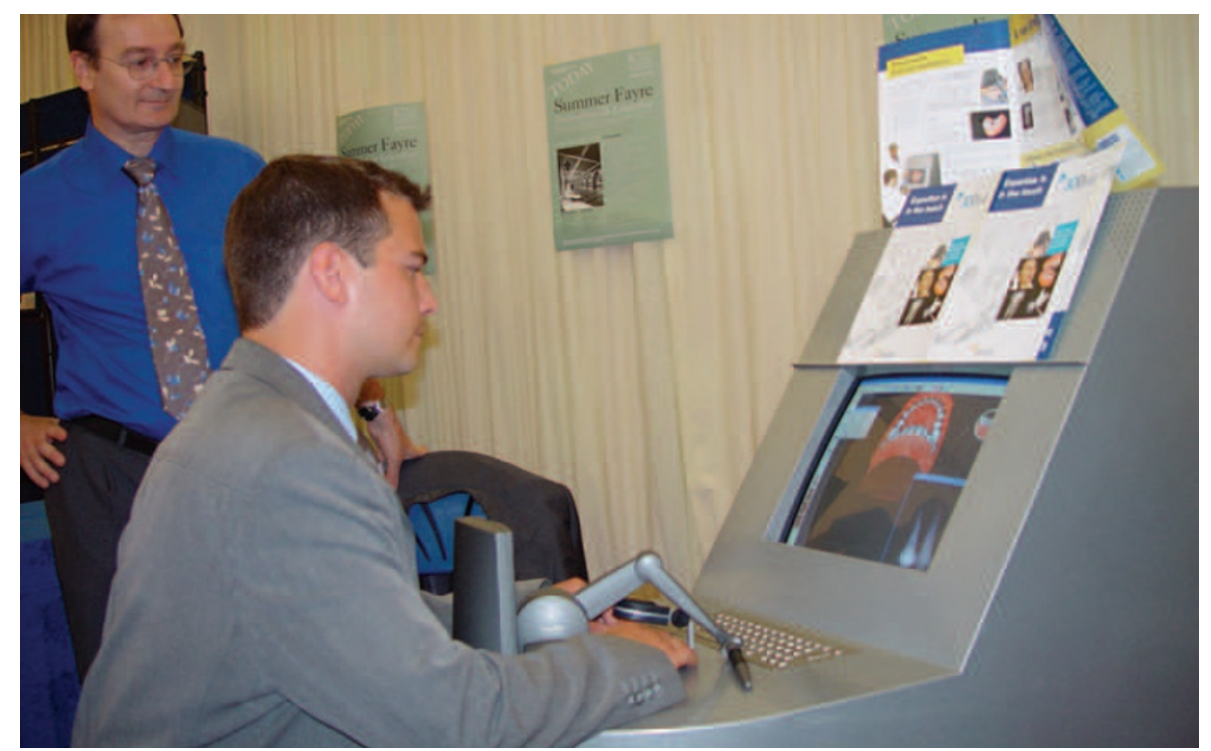

Fig. 3 The Simulife simulator

postgraduates and those in CPD, will be less tied to particular times and locations for their learning.

Undergraduates can also benefit from wireless developments. A recent trial investigated the use of personal digital assistants (PDAs) in dental teaching clinics $^{19}$ (Fig. 2). The aim of the trial was to assess the potential educational benefits of using PDAs for networked learning data collection and information processing in a clinical dental learning environment, and to consider how this can be best exploited in similar medical and dental clinical environments. The students were able to access videos of clinical dental techniques immediately before undertaking patient treatment and also to have secure access to administrative details such as forthcoming appointments.

The students had encrypted wireless access to their virtual learning environment (VLE) through which they accessed a range of teaching resources including text-based documents featuring teaching notes, illustrative images and textual extracts; PowerPoint presentations; PDF documents; instructional images; simple animations on, for example, clinical technique; and viewable webcasts for demonstrations, lectures, conferences or seminars. Other facilities included email, posting notes to bulletin boards, and entering personal or clinical data. Within the VLE a database was established to record and assess student activity through online questionnaires for the student to complete, and a logbook.

Although the students possessed a wide range of ICT skills, from novice to expert, their reaction was universally positive and the specific benefits included:

1. Being able to keep notes of their lectures and individual study

2. Being able to keep a diary of their commitments including their timetable

3. Having online access to support, particularly video material.

The PDA proved to be a highly acceptable mode of access to online education with a substantial proportion of the VLE available to students in a clinical environment.

\section{The virtual world}

Virtual reality (VR) is a human-computer interface that simulates reality. It is sometimes termed 'alternative reality'. However, it has the potential to make a significant contribution to medical training and education. Commenting on its role, one VR expert said it "provides a unique resource for education about anatomical structure. ${ }^{20}$ He went on to highlight an important benefit of the application of the technology in medicine by commenting: 'One of the main problems for medical education and training is to provide a realistic sense of the inter-relation of anatomical structures in 3D space. With VR 
the learner can repeatedly explore the structures of interest, take them apart, put them together, [and] view them from almost any perspective. ${ }^{20}$ He continued by pointing out that another advantage 'is that demonstrations and exercises, or explorations can easily be combined. ${ }^{20}$

By utilising the multimedia properties of ICT, students are able to take a tour of the structure with an expert providing a commentary to explain and describe the model. A more-than-reasonable analogy is with the flight simulators that are vital in the training of pilots. A VR simulator would 'allow surgeons to practice difficult procedures under computer control. ${ }^{20}$ Through connections via broadband in particular, virtual reality has the potential to facilitate and speed up the training of surgeons and other medical staff.

At present, as far as dental education is concerned, VR is in a trial and development phase. At one dental school, for example, a trial is being run called 'Communication Manual Skills'. It analyses videos of students and tutors interacting at the chairside. ${ }^{21}$ Large simulators already exist, for example the Dent$\mathrm{Sim}^{\mathrm{TM}}$ (http://www.denx.com) described in the first paper in this series. ${ }^{22}$ They offer training in manual skills on mannequins and can incorporate a virtual handpiece (Fig. 3). Such virtual reality aids are also likely to be important for retraining, eg for those returning to work after a family, and for CPD.

\section{Assessment}

Students will always ask 'Do I have to do this, and does it count?' The latter is often considered the main motivator for most students. Assessment can be undertaken online with little disadvantage to the student - in fact in many cases it is preferred as it can enable easier review of responses..$^{23}$ Students can prepare and submit assignments via email to the tutor or through a VLE. They are marked and returned with comments etc via the same method of communication. However, a range of other techniques can be included in a virtual learning environment including quizzes and short question and answer sessions to provide other opportunities for assessment and collaborative projects. In addition bulletin board messages can be assessed qualitatively. Results can be made available to students instantaneously and recorded in a global grade-book. Such capabilities have moved education a long way from the old school yard to a future that is truly bright.

1. Mason R. Moderating educational computer conferencing. Deosnews 1991; 1(19). www. emoderators.com/papers/mason.html (accessed 14 March 2008).

2. Microsoft Corporation. Microsoft PowerPoint 2007 users' guide. http://office.microsoft.com/engb/powerpoint/default.aspx (accessed 20 March 2008).

3. Reynolds PA, Eaton K A, Mason R. Seeing is believing: dental education benefits from developments in videoconferencing. Br Dent $J$ 2008; 204: 87-92.

4. Reynolds P A, Mason R, Eaton K A. Webcasting: casting the web more widely. Br Dent J 2008; 204: 145-149.

5. Bottino R M. The evolution of ICT-based learning environments. Br J Educ Technol 2004; 35: 553-567.

6. Asselmeyer H. Trends, current developments, and concepts in distance learning and e-Learning. Int J Comput Dent 2004; 7: 145-157.

7. Mclsaac M S, Gundawardena C N. Distance education. In Jonassen D H (ed) The handbook of research for educational communications and technology. 2nd ed. New York: Simon \&t Schuster, 2004

8. Laurillard D. Moving further towards a unified e-learning strategy - an update. London: Department for Education and Skills, 2004.
Ref: DfES/0424/2003.

9. Steinberg D C. The business model of e-learning in UK higher education. Industry and Higher Education 2004; 18: 187-198.

10. Millar B J, Reynolds P A. Blended learning pilot study in aesthetic dentistry. Proceedings of the Association for Dental Education in Europe 32nd Annual Meeting, Krakow, Poland, 2006. Abstract 44

11. Department for Education and Science. Towards a unified e-learning strategy consultation document London: DfES Publications, 2003.

12. West $W$ V. Value-on-investment and the future of e-learning in the training market. Educational Technology 2004; 44(5): 41-45.

13. Teaching and learning research programme website. Technology enhanced learning. www.tlrp. org/tel/ (accessed at 24 February 2007).

14. Wallace R M. A framework for understanding teaching with the Internet. Am Educ Res J 2004; 41: 447-488.

15. Kukulska-Hulme A, Foste-Jones J, Jelfs A, Mallett E, Holland D. Digital video applications. J Educ Media 2004; 29: 125-137.

16. Kirkwood A. Understanding independent learners' use of media technologies. Open learning. JOpen Distance Learning 2003; 8: 155-175.

17. Rowntree D G P. Developing a distance learning course. 2000. Available online at http://angelfish. open.ac.uk/pp/D.G.F.Rowntree/DL_course develpt.html (accessed at 14 March 2008).

18. King's College London Dental Institute. Fixed and removable prosthodontics MClinDent webpage. 2008. http://www.kcl.ac.uk/schools/dentistry/pg/ distance/pros/ (accessed on 18 March 2008).

19. Reynolds P A, Dunne S, Cox M, Myint Y K, Harper J Portable digital assistants (PDAs) in dentistry. Part II: pilot study of PDA use in the dental clinic. Br Dent J 2007; 202: 477-483.

20. Waterworth J A. VR in surgery is not yet healthy. A survey of the state of the art. Paper presented at Medicine Meets Virtual Reality 7. San Francisco, January 1999. Umeå: Department of Information, Umeå University, 1999.

21. Hindmarsh J, Reynolds PA, Dunne S. Managing participation in clinical dental training. Presented in a special session on Beyond the bedside: training, research and guidance in healthcare. 9th Conference of the International Institute of Ethnomethodology and Conversation Analysis (IIEMCA), Bentley College, Boston, USA, August 2005

22. Feeney L, Reynolds P A, Eaton K A, Harper J. A description of the new technologies used in transforming dental education. Br Dent J 2008; 204: 19-28.

23. Odell E W, Reynolds P A, Newton J T, Escudier M, Cox M J, Pitt-Ford T R. Online examinations: questions of design, acceptability and fairness. Dental Institute at Guy's King's College \& St. Thomas' Hospitals Profile 2006. pp 5. http://www.kcl. ac.uk/content/1/c6/02/34/87/2006.pdf (accessed on 18 March 2008). 